\title{
BIOGRAPHICAL SUMMARY
}

\section{RYOJI NOYORI}

PRESIDENT, RIKEN

AND

\section{UNIVERSITY PROFESSOR, NAGOYA UNIVERSITY}

\section{Address:}

RIKEN, 2-1 Hirosawa, Wako, Saitama 351-0198, Japan.

Telephone +81-48-462-1111, Fax +81-48-462-4604, E-mail noyori@riken.jp

Department of Chemistry and Research Center for Materials Center, Nagoya University, Chikusa, Nagoya, Aichi 464-8602, Japan.

Telephone +81-52-789-2956, Fax +81-52-783-4177,

E-mail noyori@chem3.chem.nagoya-u.ac.jp

\section{Birth:}

Kobe, Japan; September 3, 1938.

\section{Education:}

Bachelor: Kyoto University (Professor K. Sisido), 1961.

Master: Kyoto University (Professor K. Sisido), 1963.

Ph.D.: Kyoto University (Professor H. Nozaki), 1967.

Postdoctoral Fellow: Harvard University (Professor E. J. Corey), 1969-1970.

\section{Appointments:}

Instructor, Department of Industrial Chemistry, Kyoto University, 1963-1968.

Associate Professor, Department of Chemistry, Nagoya University, 1968-1972.

Professor, Department of Chemistry, Nagoya University, 1972-2003.

Director, Chemical Instrument Center, Nagoya University, 1979-1991.

Dean, Graduate School of Science, Nagoya University, 1997-1999.

Director, Research Center for Materials Science, Nagoya University, 2000-2003.

Director, Institute for Advanced Research, Nagoya University, 2002-2003 (Honorary

Director, 2007).

University Professor, Nagoya University, 2003-present.

President, RIKEN, 2003-present.

Director, ERATO Molecular Catalysis Project of the Research Development Corporation of Japan, 1991-1996.

Science Advisor, Ministry of Education, Science and Culture, 1992-1996.

Professor, Institute for Fundamental Research of Organic Chemistry, Kyushu University, 1993-1996.

Member, Scientific Council of Ministry of Education, Science, Sports and Culture, 1996-2001.

Committee Chairman, Research for the Future Program on "Advanced Processes", Japan Society for the Promotion of Science, 1996-2002.

President, The Society of Synthetic Organic Chemistry, Japan, 1997-1999.

Member, Science and Technology Council, Ministry of Education, Culture, Sports, Science and Technology, 2001-2003. 
Senior Science Advisor, Japan Society for the Promotion of Science, 2001-2003, 2003-present.

Member, Board of Directors, Takasago International Corporation, 2001-present.

President, The Chemical Society of Japan, 2002-2003.

Guest Professor, Meijo University, 2002-present.

Member, The Japan Academy, 2002-present.

Director, Research Center for Science System, Japan Society for the Promotion of Science, 2003.

Director-General, Center for Research and Development Strategy, Japan Science and Technology Corporation, 2003.

Honorary Director, Research Center for Science System, Japan Society for the Promotion of Science, 2003-2004.

Principal Fellow (Chair), Center for Research and Development Strategy, Japan Science and Technology Agency, 2003-present.

Chair, National University Corporation Evaluation Committee, 2003-present.

Member, Central Council for Education, Ministry of Education, Culture, Sports, Science and Technology, 2005-present.

Chair, Science and Technology Council, Ministry of Education, Culture, Sports, Science and Technology, 2005-present.

Member, Science Council of Japan, 2005-present.

Chair, Education Rebuilding Council, 2006-2008.

Chair, Global COE Program, Japan Society for Promotion of Science, 2007-present.

Head of the Official Suite, The Visit of the Emperor and Empress to Europe, 2007.

Member, Education Rebuilding Conference, 2008-.

\section{Publications:}

Over 500 (original papers, reviews, chapters, commentaries, and monographs).

\section{Patents:}

Over 250.

\section{Field of Research:}

Organic chemistry including synthetic organic chemistry, main-group and transition metal organic chemistry, molecular catalysis, asymmetric synthesis, new reaction media, green chemistry, physical organic chemistry, in vivo molecular science, etc. Synthesis of terpenes, alkaloids, antibiotics, prostaglandins, carbohydrates, nucleosides, nucleotides, and certain significant artificial compounds.

\section{Memberships:}

The Chemical Society of Japan (Honorary Member, 1998; President-Elect, 2001;

President, 2002; Chairman of the 125th Anniversary Project, 2003;

Chairman of the 42nd International Chemistry Olympiad, 2006-present).

The Pharmaceutical Society of Japan (Honorary Member, 2002).

The Society of Synthetic Organic Chemistry, Japan (Vice President, 1994-1996;

President, 1997-1999; Honorary Member, 2002).

The Kinki Chemical Society (Honorary Member, 2002).

The American Chemical Society.

The Royal Society of Chemistry (Honorary Fellow, 2000).

American Association for the Advancement of Science (Fellow, 1996).

The Japan-Sweden Society (Honorary Member, 2002).

The Tsukuba Science Academy (Honorary Fellow, 2002). 
The Matsunaga Prize, The Matsunaga Memorial Foundation, 1978.

The Chunichi Cultural Prize, Chunichi Newspaper Co., 1982.

The Chemical Society of Japan Award for 1985.

Award from Taipei Prostaglandin Conference and Academia Sinica, 1988.

The Naito Foundation Research Prize for 1988, The Naito Science Foundation.

The Fluka Prize, Reagent of the Year 1989, Fluka Chemie AG, Switzerland.

The Centenary Medal, The Royal Society of Chemistry, UK, 1989.

The Toray Science \& Technology Prize, The Toray Science Foundation, 1990.

The Merck-Schuchardt Chair, BOSS, Belgium, 1990.

The J. G. Kirkwood Award, The American Chemical Society/Yale University, 1991.

The Asahi Prize for 1992, The Asahi Culture Foundation.

The Tetrahedron Prize for Creativity in Organic Chemistry, Pergamon Press, UK, 1993.

The Keimei Life Science Prize (inaugural), The Keimei Foundation, 1994.

The Japan Academy Prize, 1995.

The Arthur C. Cope Scholar Award, The American Chemical Society, 1996.

The Bonn Chemistry Award, University of Bonn and Pinguin Foundation, 1996.

The Arthur C. Cope Award, The American Chemical Society, 1997.

The Chirality Medal, International Symposium on Chiral Discrimination, 1997.

The George Kenner Award, The University of Liverpool, 1997.

The King Faisal International Prize for Science, The King Faisal Foundation, 1999.

The Cliff S. Hamilton Award, University of Nebraska, 1999.

ISI Citation Laureate Award, ISI/Thomson Scientific Inc., Tokyo, 2000.

The Special Award, The Society of Synthetic Organic Chemistry, Japan, 2001.

The Wolf Prize in Chemistry, The Wolf Foundation, 2001.

The Roger Adams Award in Organic Chemistry, The American Chemical Society, 2001.

Original Member of "Highly Cited Researchers" in Chemistry, ISI/Thomson Scientific Inc., 2001.

The Nobel Prize in Chemistry, The Nobel Foundation, 2001.

The Luigi Sacconi Medal, The Italian Chemical Society (Inorganic Chemistry Division) and the Luigi Sacconi Medal Foundation, 2002.

Gold Medal, Scientific Partnership Foundation, Russia, 2003.

Molecular Chirality Award, Molecular Chirality Research Organization, 2006.

The Amedeo Avogadro Gold Medal, The Italian Chemical Society, 2006.

Person of Cultural Merit, The Japanese Government, 1998.

The Order of Culture, The Japanese Emperor/Government, 2000.

Celebration, The Chemical Society of Japan, 2001.

Scientific Manifestation, Aichi Prefecture, Japan, 2001.

Celebration, Nagoya University, 2001.

Scientific Manifestation, Nagoya City, Japan, 2002.

Celebration, The House of Representatives, Japan, 2002.

Celebration, The House of Councilors, Japan, 2002.

Trophy and Celebration, the Prime Minister of Japan, 2002.

Honorary Citizen, Nisshin City, Japan, 2002.

Honorary Degree (Dr. Rer. Nat. H. C.), Technische Universität München, 1995.

Honorary Degree (Docteur Honoris Causa), University of Rennes, 2000.

Honorary Professor, Shanghai Institute of Organic Chemistry, 2001.

Distinguished Honorary Professor, Hong Kong Polytechnic University, 2002.

Honorary Professor, South China University of Technology, 2002.

Honorary Degree (Laurea Honoris Causa), University of Bologna, 2002.

Honorary Degree (Doctor Honoris Causa), University of Alicante, 2003.

Honorary Degree (Honorary Doctor), Uppsala University, 2003. 
Honorary Degree (Doctor of University), University of Ottawa, 2003.

Honorary Degree (Doctor of Science), University of Chicago, 2003.

Honorary Degree (Dr. Nat. Honoris Causa), RWTH Aachen University, 2005.

Honorary Doctor Degree, Nanjing University of Science and Technology, 2007.

Distinguished Honorary Professor, Jiangsu University, 2007.

Honorary Professor, Xi’an Jiaotong University, 2007.

Honorary Director, Institute for Advanced Research, Nagoya University, 2007.

Honorary Degree (Doctor of Science Honoris Causa), Hong Kong Polytechnic University, 2007.

Honorary Professor, Shanghai Jiao Tong University, 2008.

Honorary Professor, Institute of Chemistry, The Chinese Academy of Sciences, 2008.

Honorary Professor, Peking University, 2008.

Honorary Degree (Honorary Doctor of Science), Hanyang University, 2008.

Fellow, The American Association for the Advancement of Science, 1996.

Honorary Member, The Chemical Society of Japan, 1998.

Honorary Fellow, The Royal Society of Chemistry (London), 2000.

Foreign Honorary Member, The American Academy of Arts and Sciences, 2001.

Honorary Member, The European Academy of Sciences and Arts (Vienna and Salzburg), 2001.

Honorary Member, The Society of Synthetic Organic Chemistry, Japan, 2002.

Honorary Member, The Pharmaceutical Society of Japan, 2002.

Honorary Member, The Kinki Chemical Society, 2002.

Academician, The Pontifical Academy of Sciences, Vatican City, 2002.

Honorary Member, The European Academy of Sciences (Brussels), 2002.

Titular Member, The European Academy of Arts, Sciences and Humanities (Paris), 2002.

Member, The Japan Academy, 2002.

Foreign Associate, The National Academy of Sciences, USA, 2003.

Foreign Member, The Russian Academy of Sciences, 2003.

Honorary Member, National Museum of Emerging Science and Innovation, 2003.

Honorary Foreign Member, The National Academy of Sciences, Republic of Korea, 2005.

Foreign Member, The Royal Society of London for Improving Natural Knowledge, 2005.

Foreign Member, The Polish Academy of Sciences, 2005.

Fellow, Federation of Asian Chemical Societies, 2005.

Distinguished Honorary Member, Catalysis Society of Japan, 2007.

Founding the Ryoji Noyori Prize, The Society of Synthetic Organic Chemistry, Japan (sponsored by Takasago International Co.), 2002. 